\title{
Properties evaluation of silorane, low-shrinkage, non-flowable and flowable resin-based composites in dentistry
}

Rodrigo Maia, Rodrigo S Reis, Andre AFVM Moro, Cesar Perez, Bárbara Pessôa, Katia Dias

(Purpose) This study tested the null hypothesis that different classes of direct restorative dental materials: silorane-based resin, low-shrinkage and conventional (non-flowable and flowable) resin-based composite (RBC) do not differ from each other with regard to polymerization shrinkage, depth of cure or microhardness. (Methods) 140 RBC samples were fabricated and tested by one calibrated operator. Polymerization shrinkage was measured using a gas pycnometer both before and immediately after curing with $36 \mathrm{~J} / \mathrm{cm}^{2}$ light energy density. Depth of cure was determined, using a penetrometer and the Knoop microhardness was tested from the top surface to a depth of $5 \mathrm{~mm}$. (Results) Considering polymerization shrinkage, the authors found significant differences $(p<0,05)$ between different materials: non-flowable RBCs showed lower values compared to flowable RBCs, with the silorane-based resin presenting the smallest shrinkage. The low shrinkage flowable composite performed similarly to non-flowable with significant statistical differences compared to the two other flowable RBCs. Regarding to depth of cure, lowshrinkage flowable RBC, were most effective compared to other groups. Microhardness was generally higher for the non-flowable vs. flowable RBCs $(p<0.05)$. However, the values for low-shrinkage flowable did not differ significantly from those of non-flowable, but were significantly higher than those of the other flowable RBCs. (Clinical Significance) RBCs have undergone many modifications as they have evolved and represent the most relevant restorative materials in today's dental practice. This study of low-shrinkage RBCs, conventional RBCs (non-flowable and flowable) and silorane-based composite - by in vitro evaluation of volumetric shrinkage, depth of cure and microhardness - reveals that although filler content is an important determinant of polymerization shrinkage, it is not the only variable that affects properties of materials that were tested in this study. 
2 Rodrigo R. Maia ${ }^{1 *}$

3 Rodrigo S. Reis ${ }^{2}$

4 André F.V. Moro ${ }^{3}$

5 Cesar R. Perez ${ }^{3}$

6 Bárbara M. Pessôa ${ }^{3}$

$7 \quad$ Katia R. H. C. Dias ${ }^{4}$

8

9 1- Assistant Professor - Department of Operative Dentistry, University of Iowa, Iowa City - USA

10 2- Post-Graduate Program Coordinator, Pontificial Catholic University, Rio de Janeiro, RJ - Brazil

11 3- Department of Dentistry, State University of Rio de Janeiro, Rio de Janeiro, RJ - Brazil

12 4- Department of Dental Clinic, Federal University of Rio de Janeiro, Rio de Janeiro, RJ - Brazil

13 *Corresponding author - email: rodrigo-maia@uiowa.edu \# Ad: S 234, University of Iowa, 52242-

141001 - Iowa City - USA

15

16

17

18

19

20

21

22

23

24

25

26 ABSTRACT 
27 (Purpose) This study tested the null hypothesis that different classes of direct restorative dental

28 materials: silorane-based resin, low-shrinkage and conventional (non-flowable and flowable) resin-

29 based composite (RBC) do not differ from each other with regard to polymerization shrinkage, depth

30 of cure or microhardness.

31 (Methods) $140 \mathrm{RBC}$ samples were fabricated and tested by one calibrated operator. Polymerization

32 shrinkage was measured using a gas pycnometer both before and immediately after curing with 36

$33 \mathrm{~J} / \mathrm{cm}^{2}$ light energy density. Depth of cure was determined, using a penetrometer and the Knoop

34 microhardness was tested from the top surface to a depth of $5 \mathrm{~mm}$.

35 (Results) Considering polymerization shrinkage, the authors found significant differences $(\mathrm{p}<0,05)$

36 between different materials: non-flowable RBCs showed lower values compared to flowable RBCs,

37 with the silorane-based resin presenting the smallest shrinkage. The low shrinkage flowable composite

38 performed similarly to non-flowable with significant statistical differences compared to the two other

39 flowable RBCs. Regarding to depth of cure, low-shrinkage flowable RBC, were most effective

40 compared to other groups. Microhardness was generally higher for the non-flowable vs. flowable

41 RBCs $(p<0.05)$. However, the values for low-shrinkage flowable did not differ significantly from those

42 of non-flowable, but were significantly higher than those of the other flowable RBCs.

43 (Clinical Significance) RBCs have undergone many modifications as they have evolved and represent

44 the most relevant restorative materials in today's dental practice. This study of low-shrinkage RBCs,

45 conventional RBCs (non-flowable and flowable) and silorane-based composite - by in vitro evaluation

46 of volumetric shrinkage, depth of cure and microhardness - reveals that although filler content is an

47 important determinant of polymerization shrinkage, it is not the only variable that affects properties of 48 materials that were tested in this study. 


\section{INTRODUCTION:}

When dental resin-based composite $(\mathrm{RBC})$ is light cured, stresses develop as a result of the polymerization contraction that accompanies setting, and they may be transferred to the bonded margins of the restoration ${ }^{1-5}$. The magnitude of these potentially damaging stresses is a function of certain characteristics of the material, such as its composition (particularly the filler concentration), the reaction kinetics and the degree of conversion of the polymeric matrix ${ }^{1-4}$.

The filler content of each $\mathrm{RBC}$ is directly related to the mechanical properties and wear resistance of the polymerized product. High volume (\%) of different fillers are fundamental to minimizing shrinkage of the composite during polymerization ${ }^{6}$. As the filler content influences both the elastic modulus and volumetric shrinkage, the amount of filler present in an RBC is a major determinant of polymerization contraction stress ${ }^{7}$, which ultimately affects the integrity of the restoration margin ${ }^{1-3}$.

Flowable RBCs differ from their conventional ("non-flowable") counterparts in that they contain substantially less (as much as $25 \%$ by weight) filler than conventional $\mathrm{RBC}^{8}$, and several studies have shown significant differences in the elastic modulus and volumetric shrinkage between materials of these two classes ${ }^{2,9}$. Although the high volumetric shrinkage that characterizes flowable composite materials may lead to high stress values, it is possible that their low elastic modulus could compensate to some degree for the stress buildup, by helping to maintain the marginal seal and integrity of the restoration ${ }^{2}$. Although flowable RBCs generally have a lower elastic modulus than their non-flowable counterparts, in some cases the elastic modulus may not be low enough to provide significant stress relief, as has been observed in studies evaluating unfilled resins ${ }^{1}$.

Efforts to overcome clinical deficiencies of RBCs have led to the development of new matrix materials ${ }^{10}$. Siloranes have been suggested as alternatives to methacrylates as components of the RBC polymer matrix, due to their hydrophobicity and low polymerization shrinkage ${ }^{11-12}$. Siloranes are 
73 hybrid systems that contain both silorane and oxirane-based monomers. The individual components of

74 the base resin silorane combined provide two main advantages: low polymerization shrinkage, due to

75 ring opening of the oxirane monomer; and increased hydrophobicity, due to the nature of siloxane

76 species. This system compensates for contraction-induced stress by opening of the oxirane ring during

77 polymerization. The advantage of the hydrophobicity of this restorative material is that it leads to lower

78 absorption of pigments present in the diet, and may reduce the potential for the adhesion of oral

79 biofilms ${ }^{12}$. Additionally, silorane monomers produce RBC systems with better biocompatibility and

80 margin integrity, as well as lower water absorption and solubility relative to methacrylate-based $81 \mathrm{RBCs}^{13}$.

82 The aim of this study was to measure and compare polymerization shrinkage, depth of cure, and 83 Knoop microhardness (KHN) among low-shrinkage to conventional (non-flowable and flowable) 84 RBCs. The tested hypotheses are that: Silorane and low- shrinkage RBCs will present lower 85 polymerization shrinkage; overall shrinkage of the conventional flowable and non-flowable RBCs is 86 related indirectly to their filler content volumes; and low-shrinkage RBCs will have the greatest depth 87 of cure. Therefore this in vitro study tested the null hypothesis that different restorative materials: 88 low-shrinkage, conventional (non-flowable and flowable) RBCs and silorane not differ from each other 89 with regard to polymerization shrinkage, depth of cure and microhardness.

\section{METHODS AND MATERIALS}

\section{Materials selection and specimen preparation}

In this study, seven restorative dental materials (Table 1) of $\mathrm{A} 2 / \mathrm{U}$ shade were selected to minimize the effects of colorants on the light polymerization. All samples were fabricated and tested

95 by one calibrated operator. Materials were evaluated for percentage of filler volume and matrix 96 monomer variation within the major categories of restorative RBC: conventional non-flowable $(C)$, 
97 flowable (F) or low-contraction (L). Regarding to the material type based on the filler size, 2 different 98 groups are present in this study: Nanofilled and Mycro-hybrid RBCs.

\section{Polymerization shrinkage}

Ten samples per group $(\mathrm{n}=70)$ were fabricated by placing the material in a $4 \mathrm{~mm}$ diameter by 2 $\mathrm{mm}$ height stainless steel molds. After the molds were filled, they were placed into a calibrated gas pycnometer AccuPyc ${ }^{\mathrm{TM}}$ 1340, Micromeritics ${ }^{\circledR}$, and the volume was measured before and after light

105 Photopolymerization was performed by using a glass slide ( $2 \mathrm{~mm}$ thickness) on top of the mold to support the polywave LED tip (Ultra-Lume LED5 at $600 \mathrm{~mW} / \mathrm{cm}^{2}$, Ultradent, South Jordan, UT, USA) delivering $36 \mathrm{~J} / \mathrm{cm}^{2}\left(600 \mathrm{~mW} / \mathrm{cm}^{2}\right.$ as measured with a LED radiometer 910726 , Kerr, Orange, CA,

108 USA) of light energy to each specimen to ensure that all brands and ranges of materials were 109 completely cured.

111 The polymerization shrinkage was calculated using the equation:

$112 P S=\underline{\mathrm{V}}_{\mathrm{i}}-\mathrm{V}_{\mathrm{f}} \times 100$

$113 \quad \mathrm{~V}_{\mathrm{i}}$

114 where $\mathrm{PS}$ is the polymerization shrinkage (in $\%$ ), $\mathrm{V}_{\mathrm{i}}$ is the volume of unpolymerized $\mathrm{RBC}$ and $\mathrm{V}_{\mathrm{f}}$ is the 115 volume of polymerized RBC.

\section{Depth of cure}

118 There is disagreement over the best depth of cure evaluation for RBCs. Among the available tests, 119 those assessing the degree of conversion, microhardness and scraping are the most reliable ${ }^{14}$. 
120 Independent of the test used, the depth of cure needs to take into account the depth at which the 121 transition between the glassy and rubbery state of the resin matrix occurs ${ }^{15}$.

122 The depth of cure was determined using a circular stainless steel split mold (6mm diameter by

$1235 \mathrm{~mm}$ height). Ten samples per group $(\mathrm{n}=70)$ were prepared by using the same light curing unit and the

124 amount of energy described previously. A Microtester (Instron Corporation, Model No. 4206) was

125 used as a penetrometer, according to the methodology of Harrington and Wilson (1993) ${ }^{16}$. Immediately

126 after light curing, the molds were inverted such that the unexposed surface (bottom) faced the

127 penetration needle. Pulses of a $12.5 \mathrm{~N}$ force (1250 grams) were applied using a $0.5 \mathrm{~mm}$ diameter needle,

128 at a rate of $1 \mathrm{~mm} / \mathrm{min}$, to the middle of the bottom, and the depth of penetration was measured digitally

129 at this point. Depth of cure was calculated using the formula: Depth of cure $=$ Depth of mold - Depth of 130 penetration.

\section{Knoop microhardness (KHN)}

133 After depth of cure was measured, the same specimens $(n=70)$ were subjected to testing of KHN 134 using a Digital Microhardness Tester (Matsuzawa Co., Ltd. Model no. MMT-X7 Toshima, Kawabe, 135 Japan). The top, light-exposed surface of each specimen was placed directly below the Knoop diamond 136 indenter, and a 500g load was applied using the indenter, with a dwell time of 15 seconds. The 137 indentation on the top surface was measured at $100 \mathrm{X}$ magnification. The KHN corresponding to each 138 indentation was computed by measuring the dimensions of the indentation and using the formula KHN $139=14.2 \mathrm{X}\left(\mathrm{F} / \mathrm{d}^{2}\right)$, where $\mathrm{F}=$ test load in Newtons; $\mathrm{d}=$ longer diagonal of an indentation (in mm). After

140 determining the KHN at the top surface, the split stainless steel mold was opened and KHN values of

141 the side surfaces of the RBC specimens were measured, at 1-mm intervals and working from the top 142 surface down to the level determined as the depth of cure of the RBC sample, using the testing 143 parameters described above. The bottom value for KHN was then recorded. 


\section{Statistical analysis}

146 Statistical analysis was performed using a one-way analysis of variance (ANOVA) and a post-hoc 147 test of Student-Newman-Keuls (SNK) to segregate the materials into groups of similar behavior.0.05 148 was considered the cutoff for significance.

\section{Results}

152 The results obtained in the present study are displayed in Table 2. Included are mean values $153(\mathrm{p}<0.05)$ and for the degree of polymerization shrinkage, depth of cure and KHN for each RBC. One154 way ANOVA indicated that in each test at least one RBC produced statistically significant differences $155(\mathrm{p}<0.05)$ from the others.

156 Regarding to:

157 1) Polymerization shrinkage, the statistical analysis for the seven composite resins revealed 158 statistically significant differences. FP90 (which is based on the resin silorane) showed the lowest 159 value for shrinkage, followed by the non-flowable RBCs (Tetric N Ceram, Filtek Z350XT and Esthet$160 \mathrm{X}$ HD). SDR represents an intermediate group, with lower values of shrinkage than the other flowable 161 RBCs (FZ350F and TNF).

162 2) Depth of cure, the RBCs fell into three distinct groups. SDR exhibited the highest depth of cure.

163 A group of flowable RBCs formed the second group. The non-flowable RBCs represent the third 164 group.

165 3) Knoop microhardness, values for the seven composite resins varied widely. As expected, the 166 highest values for hardness at the top surface were exhibited by the non-flowable RBCs. Moreover, 167 when the KHN values at the bottom were evaluated, SDR had the highest value. 


\section{Discussion}

170 The results obtained in this analysis led to rejection of the stated null hypothesis, with the tested

171 RBCs showing distinct qualities with regard to polymerization shrinkage, depth of cure and

172 microhardness. The composition of an RBC determines its physical properties in polymerized form. In

173 this study, variations in the polymeric matrix and the filler concentration of new RBCs gave rise to

174 mechanical properties that could prove clinically advantageous over those of the conventional, gold-

175 standard RBCs that were tested. RBCs that are characterized by lower shrinkage and greater depth of

176 cure and by similar hardness at both the top and bottom surface could improve on the current bulk-

177 filling techniques.

178 Given that volumetric shrinkage is directly related to the organic matrix of the composite resin, it

179 was expected that SDR and silorane-based resins would shrink less than conventional methacrylate-

180 based $\mathrm{RBC}^{12}$. In addition, the amount of filler particles is related to polymerization shrinkage; non-

181 flowable RBCs, which have more filler than their flowable counterparts, typically shrink less during

182 polymerization than do flowable $\mathrm{RBCs}^{3}$. This emphasis on shrinkage is important; when high it may

183 contribute to a restoration's failure by affecting the marginal integrity, and possibly also lead to post-

184 operative sensitivity ${ }^{17}$. This study corroborates that volumetric shrinkage ascends for the tested

185 materials in the following order: silorane-based resin, non-flowable RBCs, and flowable RBCs.

186 Nevertheless, SDR presented values of volumetric shrinkage that were very similar to those of non-

187 flowable ones and significantly lower than those for other flowable RBC tested. Its inability to improve

188 on the non-flowable materials with respect to shrinkage may be due to the fact that the low contraction

189 of the resin monomer could not completely compensate for the lower percentage of filler (44\%) in this

190 RBC. 
Flowable RBCs typically have a greater depth of cure than their non-flowable counterparts. This is

192

193

194

195

196

197

198

199

200

201

202

203

204

205

206

207

208

209

210

211

212

213

because polymerization at depth is directly related to the filler's particle size and dispersion, with smaller size and greater dispersion promoting differences in scattering of the light through the material $^{14}$. SDR presented statistically significant increase in depth of cure up to $3 \mathrm{~mm}$. This is an improvement over all of the RBCs studied ${ }^{20}$, though it is also less than the $4 \mathrm{~mm}$ advertised by the manufacturer ${ }^{5}$. However, other materials also failed to meet the depth-of-cure criteria (above $2 \mathrm{~mm}$ thickness). This may be due in part to the fact that depth of cure is influenced by RBC shade.

Knoop microhardness was used as a second method to assess the depth of cure in this study, based on the discovery by Flury et al., in $2012^{19}$ that for bulk-fill materials the ISO 4049 method overestimated depth of cure compared to its determination by microhardness tests. The evaluation of top and bottom $\mathrm{KHN}$, and of the percentage reduction, revealed that the flowable RBCs generally produced lower levels of microhardness at the top. The exception was SDR, whose top KHN was significantly higher. Regarding bottom-surface KHN, SDR had the highest mean values, regardless of viscosity, among the materials evaluated in this study. Notably, the ratio of the KHN at the top vs. bottom of the specimen was the lowest in the case of SDR. This fact could be related to the higher depth of cure obtained in the present study.

\section{CONCLUSIONS}

The following conclusions may be drawn:

1- The silorane-based resin (FP90) performed as observed in previous studies, exhibiting the least polymerization shrinkage among the RBCs tested here.

2- The low shrinkage flowable composite (SDR) performed similarly to non-flowable with significant difference compared to the other flowable RBCs. 
3- All materials tested presented statistical significant differences for microhardness from the top and from the bottom.

\section{REFERENCES}

1. Braga RR, Hilton TJ, Ferracane JL. 2003. Contraction stress of flowable composite materials and their efficacy as stress-relieving layers The Journal of the American Dental Association 134:721728.

2. Braga RR, Ballester RY, Ferracane JL. 2005. Factors involved in the development of polymerization shrinkage stress in resin-composites: A systematic review Dental Materials 21:962-970.

3. Braga RR, Ferracane JL. 2004. Alternatives in polymerization contraction stress management. Critical Reviews in Oral Biolology \& Medicine 15(3):176-184.

4. Ferracane JL. 2008. Placing dental composites - a stressful experience. Operative Dentistry 33(3):247-257.

5. Asmussen E. 1985. Clinical relevance of physical, chemical and bonding properties of composite resins. Operative Dentistry 10(2):61-73.

6. Asmussen E. 1982. Restorative resins: hardness and strength us quantity of remaining double bonds. Scandinavian Journal of Dental Research 90(6):484-89.

7. Bayne SC, Thompson JY, Swift Jr EJ, Stamatiades P, Wilkerson M. 1998. A characterization of first-generation flowable composites. The Journal of the American Dental Association 129:567577. 
238 8. Labella R, Lambrechts P, Van Meerbeek B, Vanherle G. 1999. Polymerization shrinkage and 239 elasticity of flowable composites and filled adhesives. Dental Materials 15:128-37.

240 9. Furuse AY, Gordon K, Rodrigues FP, Silikas N, Watts DC. 2008. Colour-stability and gloss241 retention of silorane and dimethacrylate composites with accelerated aging. Journal of Dentistry $242 \quad 36: 945-952$.

243 10. Guggenberger R, Weinmann W. 2000. Exploring beyond methacrylates. American Journal of 244 Dentistry 13:82-84.

245 11. Weinmann W, Thalacker C, Guggenberger R. 2005. Siloranes in dental composites. Dental $246 \quad$ Materials 21:68-74.

247 12. Palin WM, Fleming GJP, Burke FJT, Marquis PM, Randall RC. 2005. The influence of short and 248 medium-term water immersion on the hydrolytic stability of novel low-shrink dental composites. 249 Dental Materials. 21:852 - 863.

250 13. DeWald JP, Ferracane JL. 1987. A comparison of four modes of evaluating depth of cure of light251 activated composites. Journal of Dental Research 66:727-30.

252 14. Leprince JG, Leveque P, Nysten B, Gallez B, Devaux J, Leloup G. 2012. New insight into the 253 “depth of cure" of dimethacrylatebased dental composites. Dental Materials 28:512-520.

15. Harrington E, Wilson HJ. 1993. Depth of cure of radiation-activated materials - effect of mould material and cavity size. Journal of Dental Research 21:305-11.

16. Lowe RA. 2010. The search for a low-shrinkage direct composite. Inside Dentistry January:78-82.

257 17. ISO-Standards. 2000. ISO 4049:2000 Dentistry-polymer-based filling, restorative and luting 258 materials. Depth of cure, Class 2 materials. Geneve: International Organization for Standardization 1st edition:1-27.

260 18. Flury S, Hayoz S, Peutzfeldt A, Hüsler J, Lussi A. 2012. Depth of cure of resin composites: Is the ISO 4049 method suitable for bulk fill materials? Dental Materials 28:521-28. 
262 19. Salerno M, Derchi G, Thorat S, Ceseracciu L, Ruffilli R, Barone AC.2011. Surface morphology 263 and mechanical properties of new-generation flowable resin composites for dental restoration. 264 Dental Materials 27:1221-1228.

265 20. Moore BK, Platt JA, Borges G, Chu TM, Katsilieri I. 2008. Depth of cure of dental resin 266 composites: ISO 4049 depth and microhardness of types of materials and shades. Operative 267 Dentistry 33:408-12.

268

269

270

271

272

273 


\section{Table 1 (on next page)}

Materials used in this study 


\begin{tabular}{|c|c|c|c|c|c|c|c|c|}
\hline \multicolumn{9}{|c|}{ Table 1 - Materials used in this study } \\
\hline $\begin{array}{c}\text { Material } \\
\text { Type/ } \\
\text { Commercial } \\
\text { name }\end{array}$ & Type & Matrix type & $\begin{array}{c}\text { Photoinitiator } \\
\text { system }\end{array}$ & Filler type & $\begin{array}{c}\text { Filler } \\
\text { loading } \\
\text { (vol\%) }\end{array}$ & Shade & Manufacturer & Batch \# \\
\hline $\begin{array}{c}\text { Mycro-hybrid } \\
\text { SureFil® } \\
\text { SDR }^{\mathrm{TM}} \text { Flow } \\
\end{array}$ & $\mathrm{F}, \mathrm{L}$ & $\begin{array}{l}\text { Polymerization } \\
\text { modulator, } \\
\text { dimethacrylate } \\
\text { resins, UDMA }\end{array}$ & CQ & $\begin{array}{l}\text { Ba-B-F-A1 silicate } \\
\text { glass, } \mathrm{SiO} 2, \mathrm{Sr}-\mathrm{A} 1 \\
\text { silicate glass, } \mathrm{TiO} 2\end{array}$ & 44 & $\mathrm{U}$ & Dentsply & 91130 \\
\hline \multicolumn{9}{|l|}{ (SDR) } \\
\hline $\begin{array}{c}\text { Mycro-hybrid } \\
\text { Tetric N Flow } \\
\text { (TNF) }\end{array}$ & $\mathrm{F}$ & $\begin{array}{l}\text { Bis-GMA, Bis- } \\
\text { EMA, UDMA, } \\
\text { TEGDMA }\end{array}$ & CQ & $\begin{array}{c}\text { Barium glass, } \\
\text { ytterbium } \\
\text { trifluoride, Ba-Al- } \\
\text { fluorosilicate glass, } \\
\text { SiO2 }\end{array}$ & 39 & $\mathrm{~A}_{2}$ & $\begin{array}{c}\text { Ivoclar } \\
\text { /Vivadent }\end{array}$ & L40758 \\
\hline $\begin{array}{c}\text { Nanofilled } \\
\text { Filtek Z350 Flow }\end{array}$ & $\mathrm{F}$ & $\begin{array}{l}\text { Bis-GMA, Bis- } \\
\text { EMA, TEGDMA }\end{array}$ & CQ & $\begin{array}{l}\text { Agregated } \\
\text { zirconia/silica } \\
\text { cluster }\end{array}$ & 55 & $\mathrm{~A}_{2}$ & 3M Espe & 1027100529 \\
\hline (FZ350F) & & & & & & & & \\
\hline $\begin{array}{l}\text { Mycro-hybrid } \\
\text { Esthet-X HD }\end{array}$ & $\mathrm{C}$ & $\begin{array}{l}\text { Bis-GMA, Bis- } \\
\text { EMA, TEGDMA }\end{array}$ & CQ & $\begin{array}{l}\text { Barium } \\
\text { fluoroborosilicate } \\
\text { glass and silica }\end{array}$ & 60 & $\mathrm{~A}_{2}$ & Dentsply & L58656 \\
\hline & & & & & & & & \\
\hline $\begin{array}{c}\text { Mycro-hybrid } \\
\text { Tetric N Ceram } \\
\text { (TNC) }\end{array}$ & $\mathrm{C}$ & $\begin{array}{l}\text { Bis-GMA, Bis- } \\
\text { EMA, UDMA }\end{array}$ & CQ & $\begin{array}{c}\text { Barium glass, } \\
\text { ytterbium } \\
\text { trifluoride, Ba-Al- } \\
\text { fluorosilicate glass, } \\
\text { SiO2 }\end{array}$ & $55-57$ & $\mathrm{~A}_{2}$ & $\begin{array}{c}\text { Ivoclar } \\
\text { /Vivadent }\end{array}$ & 026700190 \\
\hline $\begin{array}{c}\text { Nanofilled } \\
\text { Filtek Z350 XT }\end{array}$ & $\mathrm{C}$ & $\begin{array}{l}\text { Bis-GMA, Bis- } \\
\text { EMA, UDMA, } \\
\text { TEGDMA }\end{array}$ & CQ & $\begin{array}{c}\text { Agregated } \\
\text { zirconia/silica } \\
\text { cluster }\end{array}$ & 63.3 & $\mathrm{~A}_{2} \mathrm{E}$ & 3M Espe & 1026600561 \\
\hline & & & & & & & & \\
\hline
\end{tabular}




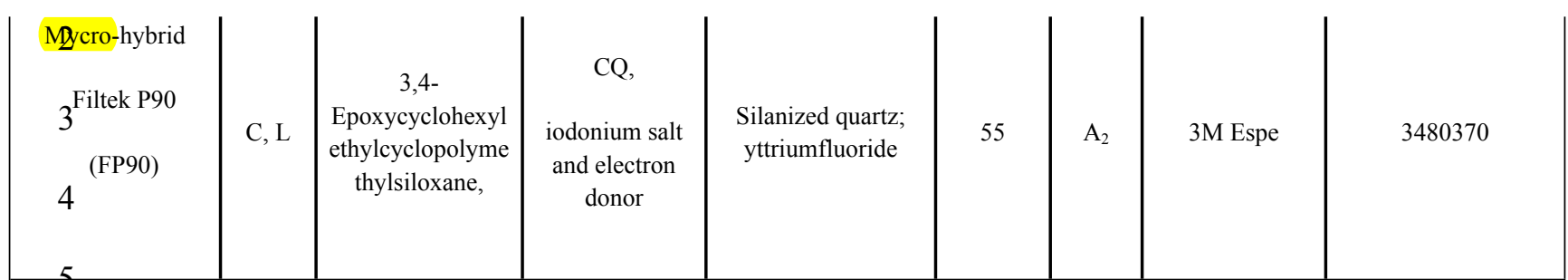

F: flowable; C: conventional; L: low-contraction; Bis-GMA: bisphenol-glycidyl-methacrylate; Bis-EMA: bisphenol-a-ethoxydimethacrylate; UDMA:

6 urethane-dimethacrylate; TEGDMA: triethyleneglycoldimethacrylate; HEMA: hydroxyethylmethacrylate; CQ: camphorquinone. 


\section{Table 2 (on next page)}

Arithmetical mean values of all tests (SD) 
2

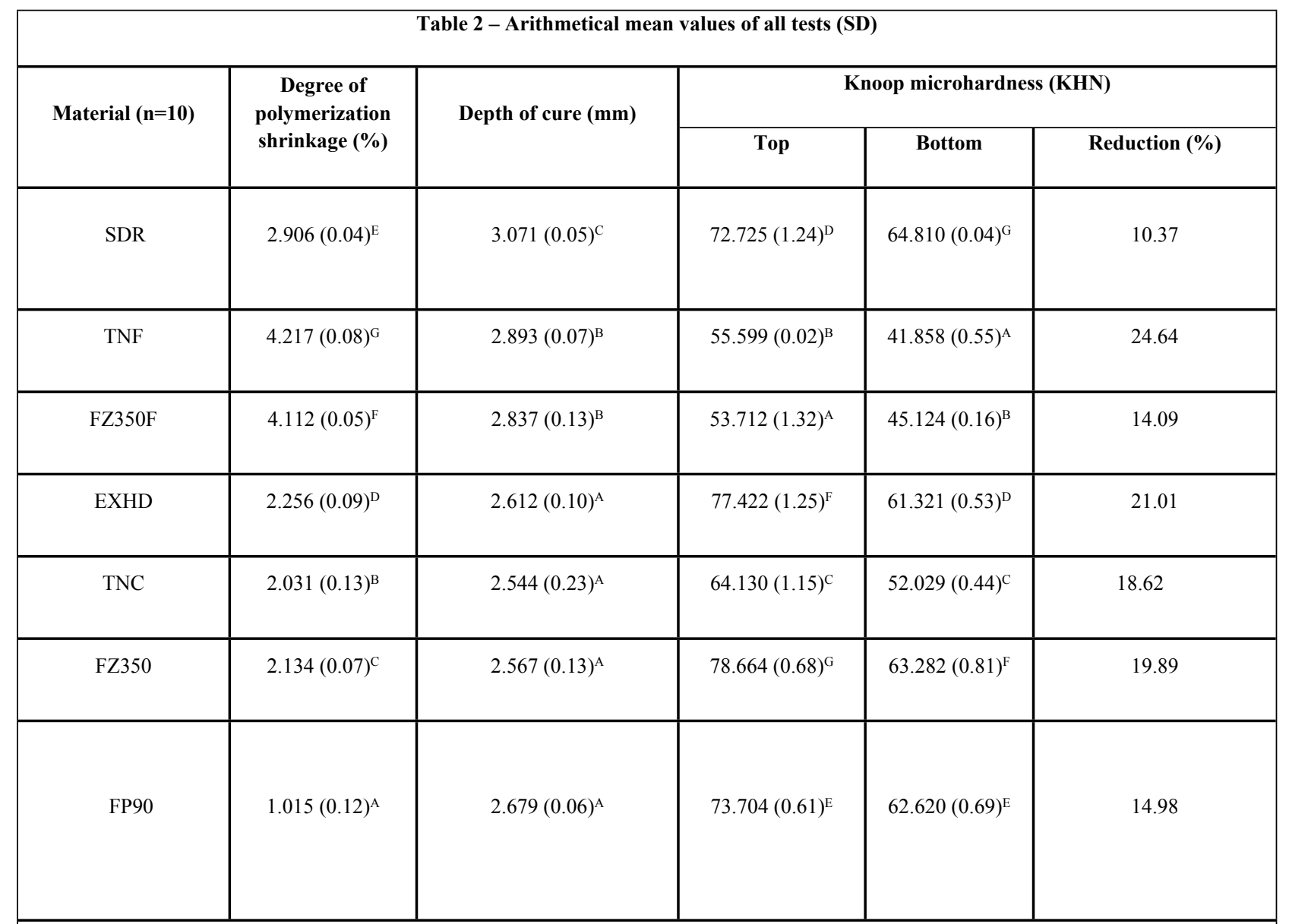

Values in each column represent the means and standard deviation (in parentheses). Upper-case letters in superscript designate groups whose $\mathrm{p}$ values for a given parameter (polymerization shrinkage, depth of cure or $\mathrm{KHN}$ ) were not statistically different $(\mathrm{p}>0.05$ ).

3

4 